Article - Agriculture, Agribusiness and Biotechnology

\title{
Tecnologic Development on Pleurotus Cultivation: Specific Practices Used in Brazil
}

\author{
María Melisa Albertia ${ }^{1}$ \\ https://orcid.org/0000-0002-6359-1253 \\ Matheus Luis Oliveira Cunha ${ }^{2}$ \\ https://orcid.org/0000-0001-8931-8557

\section{Danilo Wanderley Mendes 2} \\ https://orcid.org/0000-0001-9458-4323
}

Wagner Gonçalves Vieira Junior ${ }^{3}$

https://orcid.org/0000-0001-8843-1953

\section{Diego Cunha Zied ${ }^{2 *}$ \\ https://orcid.org/0000-0003-2279-4158}

${ }^{1}$ Instituto Tecnologico Chascomús (INTECH), Chascomús, Argentina; ${ }^{2}$ Faculdade de Ciências Agrárias e

Tecnológicas (FCAT), Universidade Estadual Paulista (UNESP), Dracena, Brazil; ${ }^{3}$ Faculdade de Ciências Agrárias e Veterinárias (FCAV), Universidade Estadual Paulista (UNESP), Jaboticabal, Brazil.

Editors-in-Chief: Paulo Vitor Farago

Associate Editor: Adriel Ferreira da Fonseca

Received: 2020.04.02; Accepted: 2020.12.18.

*Correspondence: dczied@gmail.com; Tel.: +55-18-3821-7487 (D.C.Z.)

\section{HIGHLIGHTS}

- $\quad P$. ostreatus and P. sapidus are the most productive species under the evaluated conditions.

- Different growing systems are suitable for the production of $P$. ostreatus var. Florida.

- Temperature control level affects differently the $P$. ostreatus var. Florida isolates.

- Environmental and strain factors affect yield and production parameters of $P$. ostreatus var. Florida.

Abstract: In Brazil, Pleurotus is the most important mushroom produced especially $P$. ostreatus var. Florida. In this country as in many others, the great potential for mushroom cultivation remains unexplored. Therefore, it is very important to develop new studies that allow optimizing its production. The aims of the manuscript were: i) to evaluate the productivity of six different species of Pleurotus ( $P$. citrinopileatus; $P$. djamor, $P$. ostreatus; $P$. ostreatus var. Florida; $P$. pulmonarius; $P$. sapidus); ii) to measure the effect of three different environmental conditions during cultivation of three isolates of $P$. ostreatus var. Florida. As results, $P$. ostreatus and $P$. sapidus were the most productive isolates under the evaluated conditions. Different environments produced variable effects according to the $P$. ostreatus var. Florida isolates, being possible to observe a highly plastic strain (POF 02/18), a highly sensitive strain (POF 03/18) and a strain with variable responses (POF 01/18). 
Keywords: Oyster mushrooms; edible mushrooms; food production; bioconversion; agro-industrial wastes.

\section{INTRODUCTION}

According to the growth projection scenario of the United Nations, the global population will reach 9.5 billion by 2050 [1] and in the next 50 years, the planet will need to produce more food than in the last 5,000 years, and the demand for protein will double according to the Food and Agriculture Organization of the United Nations [2]. Production of animal protein is very tasking on the environment and one reason for this is the efficiency (or inefficiency) of conversion of feed into animal tissue. In addition to land use, livestock production has an enormous role in soil degradation, water depletion and pollution, impact on biodiversity and a disturbance of the nitrogen and carbon cycles [3].

Looking at all these scenarios there is a need to focus on other available food supplementary that allows to survive the future conditions and avoid malnutrition, even in Brazil, which has always had a great tradition of animal production. For this purpose one of the best resources that exists are mushrooms. Mushrooms have the highest protein production per area and time unit i.e. 100 times more than the conventional agriculture and animal husbandry through their indoor cultivation in vertical space [4]. In Brazil, Pleurotus is the most important; more than 7475 tons are harvested annually representing a $48 \%$ of the total production [5] among the most cultivated species and Pleurotus ostreatus var. Florida stands out. However, the mushroom consumption in Brazil is still low compared to the European countries, where mushroom consumption is high and where families include mushroom cultivation as a domestic activity [6].

The price of mushrooms in the Brazilian market is very high, probably due to the lack of standardized technologies and consequent unstable production, in addition to other reasons. For many years, the mushroom cultivation technology used in Brazil was adapted from developed countries whose materials and climate were different from those of Brazil. In order to exploit the Brazilian potential for mushroom cultivation it is essential to develop cultivation technology for both, small growers and large mushroom farms [7]. Strain selection and temperature control during cultivation are among the major ecological factors that affect not only yield, but also morphological characteristics such as stalk height, stalk diameter and cap size [8]. Oyster mushroom can grow at moderate temperatures, ranging from 18 to $30^{\circ} \mathrm{C}$ [9]. However, several authors have reported very different responses to temperature condition during fruiting body induction, depending on the cultivated species of Pleurotus, or even the strain $[10,11]$. The combination of the best air temperature, moisture, nutrient conditions as well as other variables, provides a synergistic effect optimizing the production of mushrooms, with a consequent increased production and cost reduction [12].

In order to provide information regarding the agronomic performance of some of the most widespread Pleurotus species in Brazil, and some specific isolates commonly used by local laboratories/companies, the aims of this work were: i) to evaluate the productivity and others agronomic parameters of six different species of Pleurotus (P. citrinopileatus; $P$. djamor; P. ostreatus; P. ostreatus var. Florida; $P$. pulmonarius; $P$. sapidus) and; ii) to measure the effect of the environmental condition given by different growing room technological levels on the performance of three isolates of $P$. ostreatus var. Florida.

\section{MATERIAL AND METHODS}

\section{Substrate production}

Substrate production was the same for both experiments. Pleurotus substrate was prepared using a method of short composting, totaling 8 days of substrate preparation, 6 days for Phase I and 2 days for Phase II (semi-composted system). During Phase I process, $500 \mathrm{~kg}$ of Brachiaria dictyoneura and $500 \mathrm{~kg}$ of sugarcane bagasse (bulk material) were moistened for 2 days. On the 3th day, the pile was assembled and on the 4th day, the pile was turned. Then, the additional materials were added: rice and wheat bran (15 kg of each), calcitic limestone and gypsum (10 kg of each). Afterwards, two more turns were performed and at the 7th day the substrate was transferred to a pasteurization chamber (Phase II). The substrate was pasteurized at $68^{\circ} \mathrm{C}$ during 24 hours and subsequently conditioned between 52 and $48{ }^{\circ} \mathrm{C}$ for one day. After the Phase II process, the chemical characteristics of the substrate were analyzed (using three substrate samples for each nutrient). 


\section{Pleurotus species}

The strains evaluated in the first experiment were the following: PCI 01/18 ( $P$. citrinopileatus); PDJ 01/18 (P. djamor); POS 01/18 (P. ostreatus); POF 01/18 ( $P$. ostreatus var. Florida); PPU 01/18 (P. pulmonarius) and PSA 01/18 (P. sapidus). In the second experiment POF 01/18, POF 02/18 and POF 03/18 isolates of $P$. ostreatus var. Florida were used. These isolates were obtained from different growers from Sao Paulo and Parana States (Brazil). They were deposited in the public culture collection of Sao Paulo State University, Dracena Campus, with open access to other researchers.

\section{Inoculation}

A number of 16 holes were made in all bags $(1.8 \mathrm{~cm}$ of diameter) previous the substrate inoculation. After phase II process the spawn was thoroughly mixed with the substrate ( $2 \%$ of wet substrate). The mixture were packed into plastic bags ( $2 \mathrm{~kg}$ wet substrate) and for the first experiment substrate bags were incubated during 13 days in the mushroom house used specifically for Pleurotus cultivation, at $75 \pm 5 \%$ relative humidity, and without ventilation. Under these conditions, the substrate temperature was kept at $26 \pm 2{ }^{\circ} \mathrm{C}$. For the second experiment, incubation was carried out in the growing systems (controlled, semi-controlled and low controlled), which the environmental variables were influenced according to the technological degree of the cultivation environment.

\section{Growing and harvest conditions}

For both experiments, relative humidity during cropping period was $85 \pm 10 \%$. For the first experiment, temperature was $25 \pm 3{ }^{\circ} \mathrm{C}$. For the second experiment, temperature conditions variated according to the cultivation environment (controlled, semi-controlled and low controlled). Mushrooms were collected twice a day during each flush, weighed and counted for the analysis of the production parameters.

\section{Evaluated parameters}

The Automatic Meteorological Station recorded weather conditions during the cultivation period. The following production parameters were evaluated in both experiments: i) the yield calculated as 100 times the fresh weight (f.w.) of mushrooms divided by the f.w. of substrate, expressed as a percentage; and ii) the clusters mean weight calculated as weight of clusters harvested divided by the cluster number. Also, for the second experiment were measured: iii) the number of clusters harvested; iv) the mushroom number; v) mushroom mean weight calculated as total f. w. harvested during the cycle divided by the mushroom number; and vi) the production distribution (\%) through the days of crop period.

\section{Experimental details and statistical analyses}

The first experiment was done in a completely randomized design with six replicates (bag with $2 \mathrm{~kg}$ of substrate). Six different species of Pleurotus (each species represented a treatment) were compared in terms of productivity. The second experiment was carried out using a double factorial completely randomized design, with three isolates of $P$. ostreatus var. Florida $\times$ three environmental conditions (total controlled system; semi-controlled system that provides less variation in temperature and humidity due to the thermal insulation of the chamber with Styrofoam; and finally plastic greenhouse with only partial control of relative humidity that provides large variation in the temperature during the day).

Experiments data were submitted to analysis of variance and the means were compared by Tukey test (5\%). For each variable, the mean values and the MSD (minimum significant difference; Fisher's Least Significant Difference; alpha 0.05) were calculated.

\section{RESULTS}

Characteristics of the analyzed substrate were the following: nitrogen: $1.1 \mathrm{~g} \mathrm{~kg}^{-1}$; organic matter $931 \mathrm{~g}$ $\mathrm{kg}^{-1}$; organic carbon $83 \mathrm{~g} \mathrm{~kg}^{-1}$; C/N ratio 75/1 and $\mathrm{pH} 7.7$.

During the cultivation period, the average temperature outside recorded was $26^{\circ} \mathrm{C}$ with maximum and minimum peaks of $30^{\circ} \mathrm{C}$ and $23.2^{\circ} \mathrm{C}$, respectively. The average relative humidity $(\mathrm{RH})$ was $74.2 \%$ and the accumulated rainfall for this period was $181.5 \mathrm{~mm}$. 


\section{$1^{\text {st }}$ Experiment}

The isolates tested were photographed during fruiting (Figure 1). The two variables analyzed (yield and cluster mean weight) showed statistically significant differences (Figure 2).

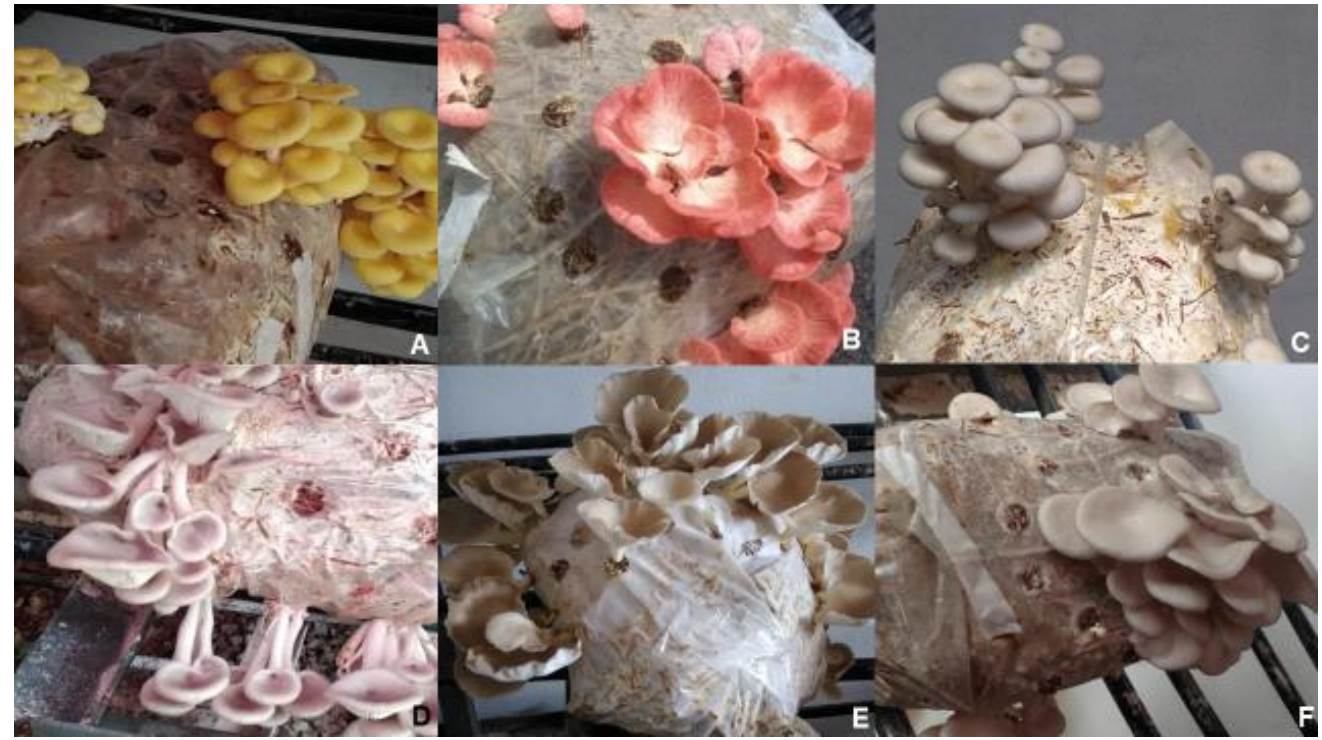

Figure 1. Pleurotus species (A: PCI 01/18; B: PDJ 01/18; C: POS 01/18; D: POF 01/18; E: PPU 01/18; and F: PSA 01/18).

Maximum yield was achieved by POS 01/18 and PSA 01/18 strains, with the values of 19.93 and $17.76 \%$, respectively. The lowest yield was for $\mathrm{PCl} 01 / 18$ (11.56\%) and PDJ 01/18 strains (12.08\%) (Figure 2). Respect to cluster mean weight PSA 01/18 strain obtained the highest registered weight $(35.87 \mathrm{~g})$, while PDJ 01/18, POF 01/18 and PPU 01/18 strains reached the lowest cluster mean weight $(11.75,18.19$ and 19.82 g, respectively).

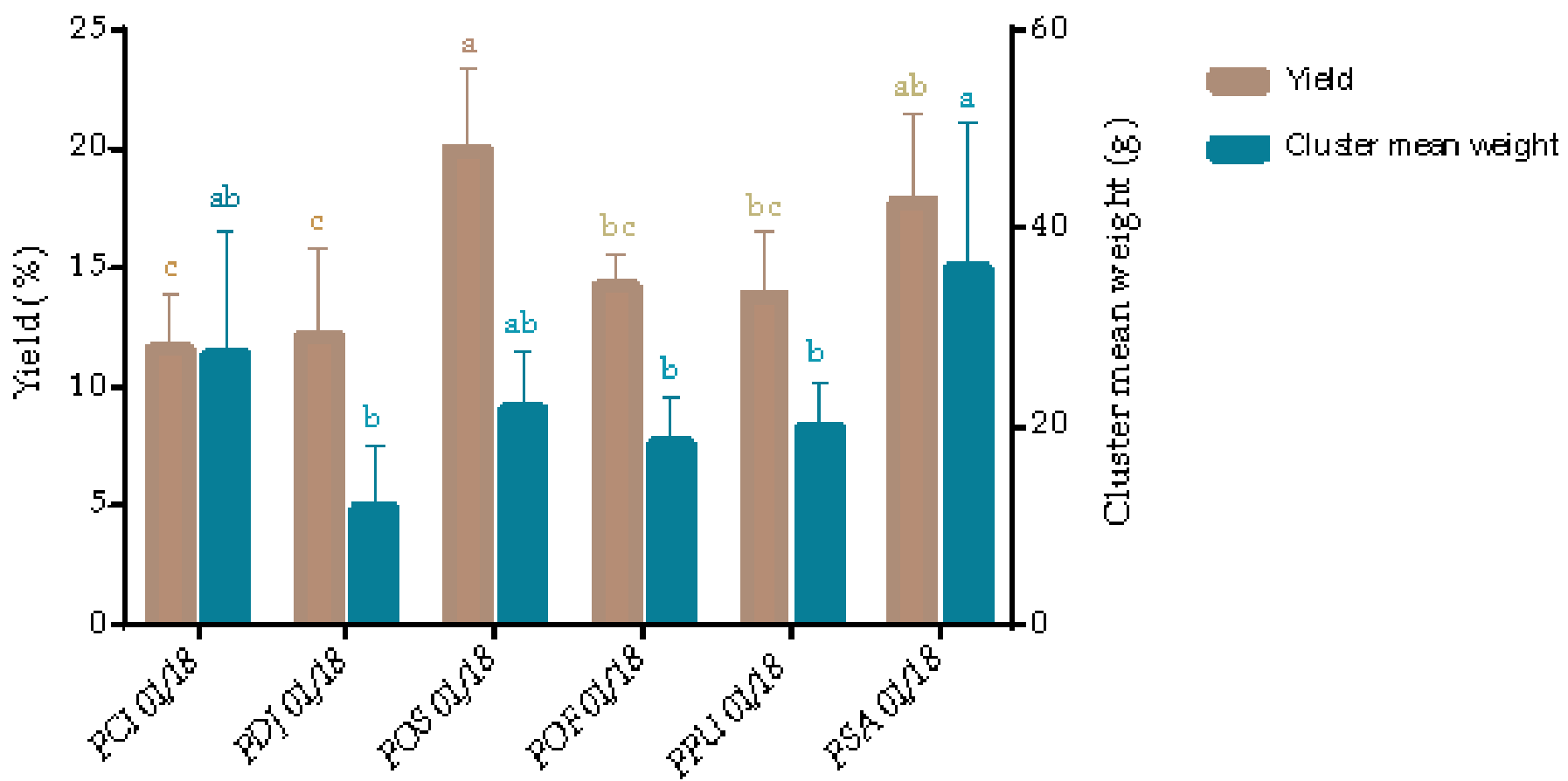

Figure 2. Yield (\%) and cluster mean weight (g) of Pleurotus species. Different letters indicate significant differences at $\mathrm{p}<0.05$ according to Tukey's test, $\mathrm{n}=6$. Yield mean: 14.8 and yield DMS: 5.3. Cluster mean weight mean 22.41 and cluster mean weight DMS: 10.68. 


\section{$2^{\text {nd }}$ Experiment}

Regarding to mushroom production, the effect of environmental conditions was observed for POF 01/18 and POF 03/18 isolates (Figure 3). POF 01/18 reached higher yield values in controlled and low controlled systems (14.57\% and $11.89 \%$, respectively) than in semi-controlled system (7.24\%). POF 03/18 reached the highest yield value in controlled system $(9.23 \%)$ and the minimum yield value in low controlled systems $(3.60 \%)$. The strain POF $02 / 18$, on the contrary, stood out for not presenting significant differences in mushroom yield in the controlled system $(8.00 \%)$, semi-controlled system $(10.12 \%)$ or low controlled system $(10.20 \%)$. Therefore, the effect of environmental conditions was dependent on the mushroom strain.

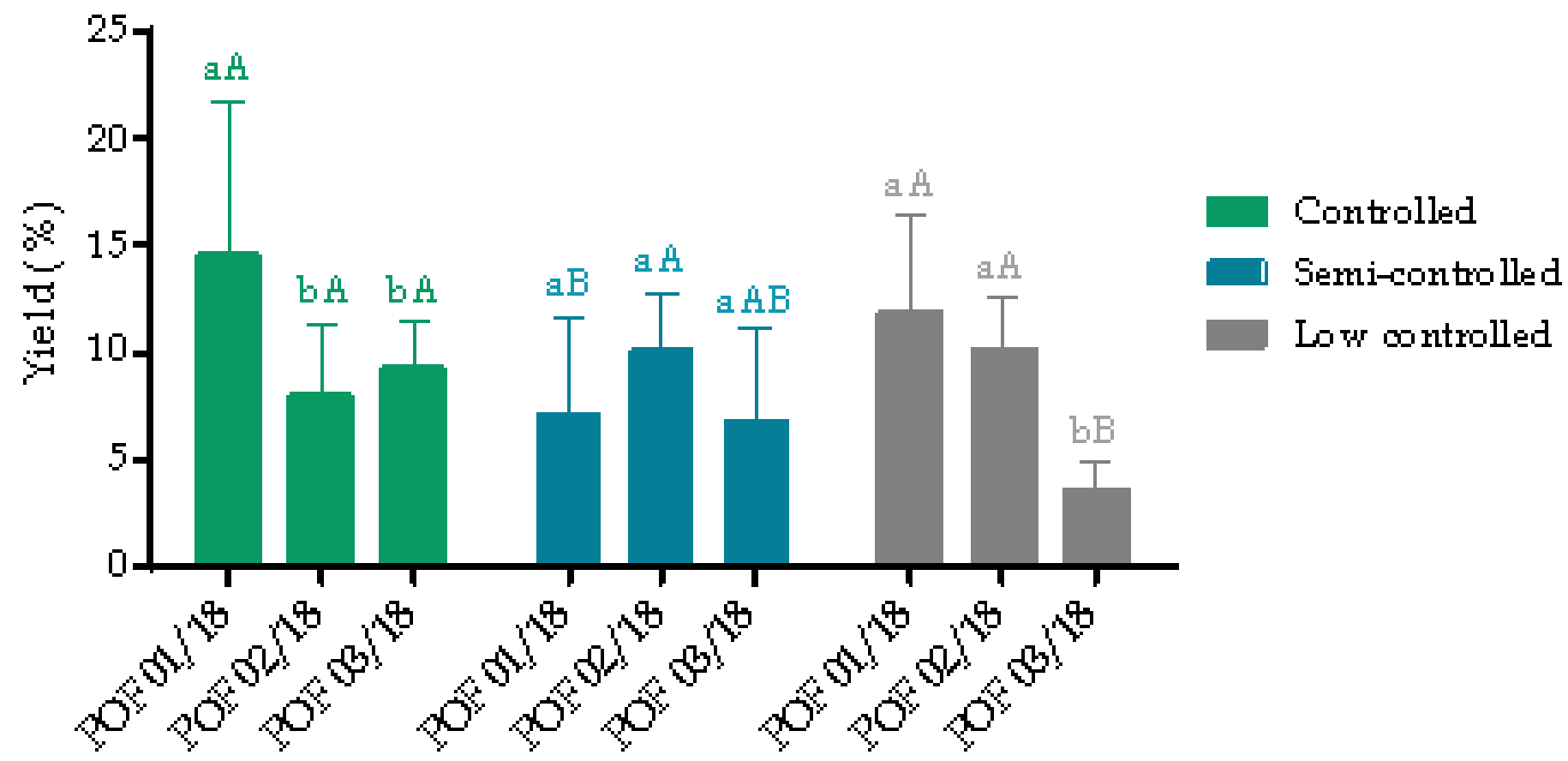

Figure 3. Yield (\%) of $P$. ostreatus var. Florida isolates in different growing systems. Different lower case letters mean significant differences between the isolates and different upper case letters mean significant differences between the growing systems at $p<0.05$ according to Tukey's test, $n=6$. Mean: 9.10; DMS: 4.70 .

All the productive parameters showed significant differences. The strain factor influenced two analyzed variables (cluster number and mushroom number) while environmental factor influenced three variables analyzed (cluster mean weight, mushroom number and mushroom mean weight) (Table 1). For the cluster number, the influence of the strain factor was verified in the low controlled system, where POF 03/18 strain presented the lowest value registered and the POF 01/18 strain presented the highest cluster number value. For the cluster mean weight, the influence of the environment factor was verified on POF 01/18 strain, it shows the highest reported value in the controlled system and the lowest value was showed for semicontrolled system. Regarding to the mushroom number, the influence of the environment for POF 03/18 strain was verified, which presented the lowest value recorded in the low controlled system and highest to semicontrolled system. POF 01/18 strain showed the highest number of mushroom harvested comparing with the others isolates in the low controlled system. Regarding to the mushroom mean weight, the influence of the environment for POF 03/18 strain was shown. This strain presented the maximum and minimum values recorded for the low controlled and semi-controlled systems, respectively. 
Table 1. Productive parameters of $P$. ostreatus var. Florida isolates in different growing systems.

\section{Growing system}

Strain

Controlled Semi-controlled

Low control Controlled

Semi-controlled

Low control

\begin{tabular}{|c|c|c|c|c|c|c|}
\hline & \multicolumn{3}{|c|}{ Cluster number } & \multicolumn{3}{|c|}{ Cluster mean weight } \\
\hline POF 01/18 & 6.83 a $A$ & 4.67 a $\mathrm{A}$ & 6.50 a $A$ & $60.24 \mathrm{a} \mathrm{A}$ & 35.49 a B & $39.18 \mathrm{aAB}$ \\
\hline POF 02/18 & 4.83 a $\mathrm{A}$ & 5.67 a A & $4.17 \mathrm{ab} A$ & 40.48 a A & 35.57 a $A$ & 55.55 a $A$ \\
\hline POF 03/18 & 4.17 a $A$ & 4.50 a $A$ & $1.75 \mathrm{~b} \mathrm{~A}$ & 50.45 a $A$ & 29.14 a $A$ & 46.02 a $A$ \\
\hline Mean & & 4.80 & & & 43.77 & \\
\hline \multirow[t]{2}{*}{ DMS } & & 3.49 & & & 21.17 & \\
\hline & \multicolumn{3}{|c|}{ Mushroom number } & \multicolumn{3}{|c|}{ Mushroom mean weight } \\
\hline POF 01/18 & 88.50 a $A$ & 59.16 a $A$ & 90.00 a $A$ & 4.10 a $A$ & 2.61 a A & 4.35 a A \\
\hline POF 02/18 & 50.33 a $A$ & 79.33 a $A$ & $55.00 \mathrm{~b} \mathrm{~A}$ & 3.26 a A & 2.45 a A & 4.36 a $\mathrm{A}$ \\
\hline POF 03/18 & 51.00 a $A B$ & 57.33 a $A$ & $15.75 \mathrm{~b} \mathrm{~B}$ & 4.35 a $A B$ & 2.39 a B & 7.31 a $A$ \\
\hline Mean & & 61.42 & & & 3.95 & \\
\hline DMS & & 42.48 & & & 3.67 & \\
\hline
\end{tabular}

Values followed by different lower case letters within a column and upper case letters within a line are significantly different at $p<0.05$, according to Tukey's test, $n=6$.

In Figure 4 it is possible to verify that for the controlled system the start and the end of production were on the 18th and 48th, respectively. In the semi-controlled system, production began on the 16th and ended on the 48th. For the low controlled system, a lower precocity was verified since the start of production was on the $23 \mathrm{rd}$ and the crop cycle ended 50 days, i.e. it lasted two more days compared to the other systems. For POF $01 / 18$ strain in controlled and low controlled systems, this strain reached $94 \%$ of its production in 35 days in the controlled system and $68 \%$ for the same period in low controlled system. Concerning to POF $02 / 18$ strain, it showed low variation in the production times since, in 35 days it reached a production of $90 \%$ for controlled system, $93 \%$ in the semi-controlled system and $85 \%$ in the low controlled system.
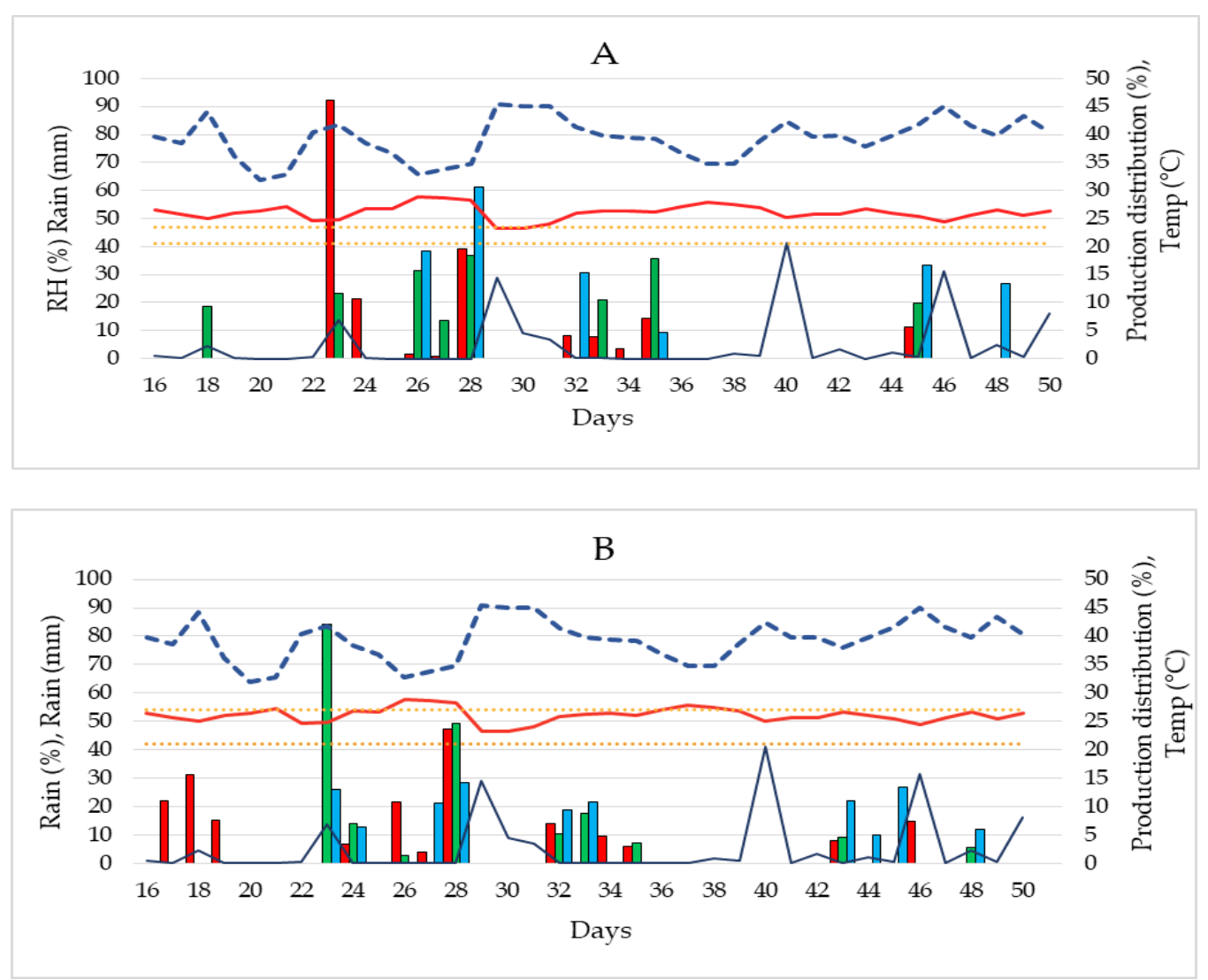


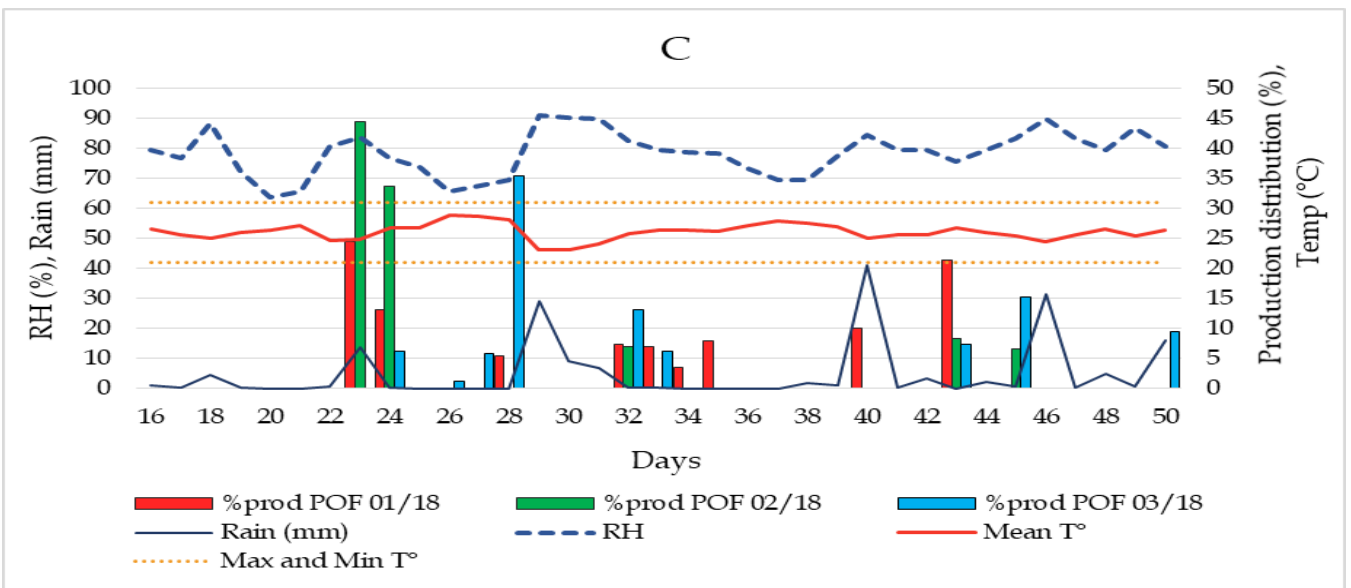

Figure 4. Production distribution (\%), weather conditions (temperature, relative humidity and rainfall) and maximum and minimum temperature range in growing system with total environmental control (A); growing system with semi environmental control (B) and growing system with low environmental control (C).

\section{DISCUSSION}

The results obtained provide information regarding the yield and the main productive characteristics of some of the most commonly Pleurotus species used in Brazil by mushroom companies and local laboratories.

\section{$1^{\text {st }}$ Experiment}

The greater performance of $P$. ostreatus is in agreement with many previous works where performance of several species of the genus Pleurotus were compared $[17,18]$. However, there are also many works where the results were different $[19,20,21]$. From the literature, yields of cultivated mushrooms always differ between fungal species, type or size of substrate, supplementation of substrates and other varying growth factors [17].

$P$. ostreatus mushroom yield (17.8\%) was similar to that obtained by [22] which used a sugarcane bagasse-based compost with Brachiaria and supplements (17\%). P. sapidus also reached a yield of $17.8 \%$, which is an intermediate value among those reported by [23,24] who reported $239 \mathrm{~g}$ and $156 \mathrm{~g}$ for each $\mathrm{kg}$ of wet substrate, whose formulation used sisal leaf waste mixed with Panicum coloratum [23] and whole cattail weed [24]. These values correspond to a yield of $23.9 \%$ and $15.6 \%$ according to the equation used in this work.

P. pulmonarius reached a yield of $13.78 \%$, which is slightly higher than those reported by [25] on maize stalk supplemented with maize flour residues (11\%). The yield of $P$. djamor (13.36\%) was slightly lower than the reported value [26] who obtained $156 \mathrm{~g}$ of fruit bodies in $750 \mathrm{~g}$ of sugarcane bagasse-based substrate, which would be equivalent to a yield of $20.8 \%$, while [27] reported $4.68 \%$ in the same substrate. In this work, $P$. ostreatus var. Florida reached a yield of $14.2 \%$ whereas Biswas and coauthors [28] reported $218 \mathrm{~g}$ of fresh mushrooms in $4.66 \mathrm{~kg}$ of sugarcane bagasse-based substrate, which is equivalent to a yield of $4.67 \%$. The yield of $P$. citrinopileatus (11.5\%) was lower than that reported by Atila [29] (19.99\%) on oak sawdust-based substrate supplemented with wheat bran and by [30] who obtained a yield of $33 \%$ on a wheat straw-based substrate.

Hoa and coauthors [31] associated the differences in terms of yield to the differences on substrate types, which include cellulose/lignin ratio, mineral contents, $\mathrm{pH}$, electrical conductivity and carbon nitrogen ratio $(\mathrm{C} / \mathrm{N})$. Bellettini and coauthors [12] lists a large number of extrinsic factors such as substrate heat treatment, cultivation room temperature, humidity and $\mathrm{CO}_{2}$ content, which affect in the performance of the Pleurotus spp.

Although $P$. ostratus var. Florida is the most cultivated species in Brazil, as it allows cultivation at high temperatures (supporting up to $31^{\circ} \mathrm{C}$ ), it is essential to highlight the importance of this study to look for alternatives of Pleurotus species for winter cultivation. Thus, the species $P$. ostreatus (POS 01/18) and $P$. sapidus (PSA 01/18) can be indicated for cultivation with temperature control about $25 \pm 3{ }^{\circ} \mathrm{C}$. It should be emphasized that the average weight of the cluster is a variable that is proportionally associated with the mushroom number per cluster and the mushroom weight, but also depends on the morphology of each species. 


\section{$2^{\text {nd }}$ Experiment}

The three growing systems evaluated were suitable for the production of different isolates of Pleurotus var. Florida. Even in the rustic plastic greenhouse, the versatility of oyster mushrooms allows their cultivation with a minimal technological investment [13], reported that Pleurotus spp. are the easiest, quickest and least expensive species to grow since it requires low cultivation technology. However, the three isolates evaluated showed different responses for both yield and some variables analyzed.

POF 03/18 isolate showed a high variation according to the cultivation system with the worst performance in the low controlled system. On the contrary, POF 02/18 strain showed no significant differences between environmental factors, which indicates a great plasticity to the different growing systems and thermal amplitude.

The results reported here emphasize the importance of adjusting the mushroom cultivation technology with the most appropriate isolates for those growing conditions. Therefore, the best isolates could be selected according to each mushroom grower, environmental conditions and mushroom facility.

It was notable that in the semi-controlled system three isolates showed the lowest values of average mushroom weight and average cluster weight, which could indicate that systems with temperatures of $24 \pm$ $3^{\circ} \mathrm{C}$ could be a good strategy to use in the production of small mushrooms of $P$. ostreatus var. Florida. Small fruit bodies tend to be more palatable because of their lower fiber content. Moreover, the large sized fruit bodies are considered as an inferior quality since such fruit bodies tend to break during packaging and decreases the shelf life, thus reducing their quality [14].

$P$. ostreatus var. Florida is a variety developed for high temperature cultivation [15]. However, a shorter time for the first harvest was observed in the controlled and semi-controlled systems for two isolates. Probably, the lower temperature may have acted as a factor in pinning [16]. This induction was absent in the low controlled system and fruiting began after registering a decrease in external temperature (Figure 2C). Similar results were reported by [10] when compared the production of $P$. florida in two different culture systems: a concrete room with $20-30^{\circ} \mathrm{C}$ and a regular thatched method with $25-30^{\circ} \mathrm{C}$, where they observed 18 and 26 days for the first harvest, respectively.

The highest yield was obtained from POF 01/18 strain in the controlled and low controlled systems. However, it is important to consider the cultivation cycle, since the highest percentage of total production in the shortest time was obtained in controlled system. In the case POF 02/18 strain, although it was not the most productive strain, it could be successfully cultivated in mushroom farms with low technological level since it was not affected either in yield or in cultivation cycles in any of three evaluated systems. Finally, POF $03 / 18$ strain could be successfully cultivated only in systems with temperature control.

\section{CONCLUSION}

According to results of the present study in first experiment under the evaluated conditions, the most productive species were $P$. ostreatus and $P$. sapidus, which could be diversification alternatives to the cultivation of $P$. ostreatus var. Florida. In second experiment, the different environments produce very different effects according to the isolate of $P$. ostreatus var. Florida used, being possible to observe a highly plastic isolate (POF 02/18), a highly sensitive (POF 03/18) and a isolate with variable responses (POF 01/18). These results suggest a genetic variability between the commercial isolates from Pleurotus ostreatus var. Florida. Thus, it is essential to select the strain that best suits the growing conditions of each mushroom growing establishment.

Acknowledgements: We would like to thank the Fundação de Amparo a Pesquisa do Estado de São Paulo for granting scholarships (18/19667-9 and 19/00419-8).

Conflicts of Interest: Declaration of interest statement Authors declare that they have no conflict of interest. 


\section{REFERENCES}

1. United Nations. World Population Prospects - Population Division - United Nations [Internet]. [Cited in March 28, 2020]. Available in: https://population.un.org/wpp/Graphs/Probabilistic/POP/TOT/900

2. FAO. Food and Agriculture Organization of the United Nations, organization. The future of food and agriculture: trends and challenges. Rome: Food and Agriculture Organization of the United Nations. 2017;163 p.

3. Morawicki RO \& Diaz DJG. Food Sustainability in the Context of Human Behavior. Yale J Biol Med. 2018;91(2):191-6.

4. Pandey VV, Kumari A, Kumar M, Saxena J, Kainthola C, Pandey A. Mushroom cultivation: Substantial key to food security. Trop. J. Appl. Nat. Sci. 2018;10(4):1325-31.

5. Sánchez JE, Zied DC, Albertó E. Edible mushroom production in the Americas. In: Abstracts of the 9th International conference on mushroom biology and mushroom products. Shanghai, China. 2018:p. 2-11.

6. de Castro LP, Maihara VA, Silva PSC, Figueira RCL. Artificial and natural radioactivity in edible mushrooms from Sao Paulo, Brazil. J. Environ. Radioact. 2012;113:150-4.

7. Dias ES. Mushroom cultivation in Brazil: challenges and potential for growth. Ciênc Agrotec. 2010;34(4):795-803.

8. Amga. The Australian Mushroom Growers Association (AMGA). Locked bag 3, 2 Forbes ST., Windsor, NSW, 2756, Australia, 2004.

9. Jaramillo Mejía S, Albertó E. Heat treatment of wheat straw by immersion in hot water decreases mushroom yield in Pleurotus ostreatus. Rev. Iberoamer Micol. 2013;30(2):125-9.

10. Ragupathi V, Kumerasan S, Selvaraju S, Karthikeyan V, Karthikeyan CV. Optimizing the growth conditions and adopting new methods growing oyster and milky mushrooms in same conditions. Int J Herb Med. 2016;4(3):1-4.

11. Zervakis G, Balis C. Comparative study on the cultural characters of Pleurotus species under the influence of different substrates and fruiting temperatures. Micol Neotrop Aplicada. 1992;5:39-47.

12. Bellettini MB, Fiorda FA, Maieves HA, Teixeira GL, Ávila S, Hornung PS, et al. Factors affecting mushroom Pleurotus spp. Saudi J Biol Sci. 2019;26(4):633-46.

13. Patel SK, Chandra R, Dhakad PK. Comparative study on growth parameters and yield potential of five species of oyster mushroom. Int. J. Pharmacogn Phytochem Res. 2019;8(4):152-6.

14. Onyango BO, Palapala VA, Axama PK, Wagai SO, Gichimu BM. Suitability of Selected Supplemented Substrates for Cultivation of Kenyan Native Wood Ear Mushrooms (Auricularia auricula). Am. J. Food Technol. 2011;6:395403.

15. Neelam S, Chennupati S, Singh S. Comparative studies on growth parameters and physio-chemical analysis of Pleurotus ostreatus and Pleurotus florida. Asian J Plant Sci. 2013;3:163-9.

16. Owaid MN, Abed AM, Nassar BM. Recycling cardboard wastes to produce blue oyster mushroom Pleurotus ostreatus in Iraq. Emir J Food Agr. 2015;27(7):537-41.

17. Familoni TV, Ogidi CO, Akinyele BJ, Onifade AK. Evaluation of yield, biological efficiency and proximate composition of Pleurotus species cultivated on different wood dusts. Czech Mycology. 2018;70(1);33-45.

18. Ashraf J, Ali MA, Ahmad W, Ayyub CM, Shafi J. Effect of different substrate supplements on oyster mushroom (Pleurotus spp.) production. Food Sci Technol. 2013;1(3):44-51.

19. Kalaw SP, Albinto RF. Growth performance and nutritional attributes of Pleurotus species grown on rice straw based formulations. Adv Environ Biol. 2015;9(18):72-81.

20. Das N, Mishra S, Biswas L, Karmakar NC. Comparative study of five Pleurotus species cultivated in warm temperature on non-sterilized rice straw. Emir J Food Agr 2015;7;49-55.

21. Adebayo EA, Oloke JK, Azeez MA, Omomowo IO, Bora TC. Assessment of the genetic diversity among ten genotypes of Pleurotus (oyster mushroom) using nutrient and mineral compositions. Sci Hortic. 2014;166:59-64.

22. Vieira FR, de Andrade MCN. Optimization of substrate preparation for oyster mushroom (Pleurotus ostreatus) cultivation by studying different raw materials and substrate preparation conditions (composting: phases I and II). World J Microbiol Biotechnol. 2016;32(11):190.

23. Mshandete AM. Cultivation of Pleurotus HK-37 and Pleurotus sapidus (oyster mushrooms) on cattail weed (Typha domingesis) substrate in Tanzania. Int J Biol Sci. 2011;1(3):135-44.

24. Muthangya M, Hashim SO, Amana JM, Mshandete AM, Kivaisi AK. Optimization of Pleurotus mushroom cultivation on saline sisal solid waste. World Appl Sci J. 2013;23(9):1146-50.

25. Mkhize SS, Zharare GE, Basson AK, Mthembu MS, Cloete J, Mkhize SS, et al. Performance of Pleurotus pulmonarius mushroom grown on maize stalk residues supplemented with various levels of maize flour and wheat bran. Food Sci Technol. 2017;37(4):570-7.

26. Hasan MT, Khatun MHA, Sajib MAM, Rahman MM, Rahman MS, Roy M, et al. Effect of wheat bran supplement with sugarcane bagasse on growth, yield and proximate composition of pink oyster mushroom (Pleurotus djamor). Am J Food Technol. 2015;3(6):150-7. 
27. Juliana K, Grandez A. Producción del hongo comestible Pleurotus Djamor (fr.) Boedijn usando distintos sustratos de residuos agrícolas aislado en Tingo Maria [Undergraduate thesis]. Universidad Nacional Agraria de la Selva (UNAS); 2017.

28. Biswas MK, Biswas SB. Recycling of ligno-cellulosic waste materials through oyster mushroom cultivation for sustainable food production. The Ecoscan. 2015;9:655-9.

29. Atila F. Evaluation of Suitability of Various Agro-Wastes for Productivity of Pleurotus djamor, Pleurotus citrinopileatus and Pleurotus eryngii Mushrooms. J Exp Agric Int. 2017;17(5):1-11.

30. Medany GM. Cultivation possibility of golden oyster mushroom (Pleurotus citrinopileatus) under the Egyptian conditions. Egypt J Agric Res. 2014;92(2):749-61.

31. Hoa HT, Wang CL, Wang CH. The Effects of Different Substrates on the Growth, Yield, and Nutritional Composition of Two Oyster Mushrooms (Pleurotus ostreatus and Pleurotus cystidiosus). Mycobiology. 2015;43(4):423-34.

() 2021 by the authors. Submitted for possible open access publication under the terms and conditions of the Creative Commons Attribution (CC BY NC) license (https://creativecommons.org/licenses/by-nc/4.0/). 